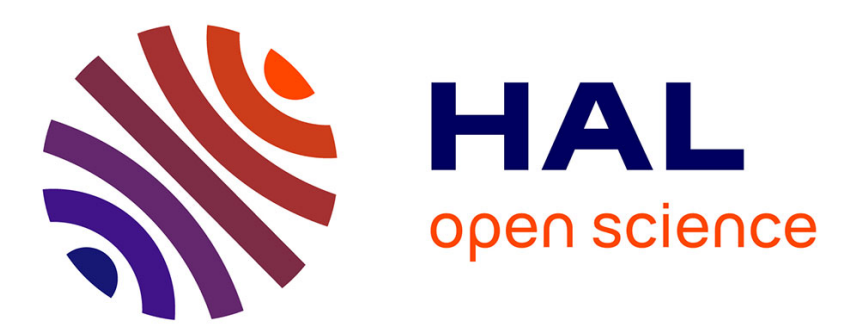

\title{
Determination of mass attenuation coefficient by numerical absorption calibration with Monte-Carlo simulations at $59.54 \mathrm{keV}$
}

D Degrelle, C Mavon, J.-E Groetz

\section{- To cite this version:}

D Degrelle, C Mavon, J.-E Groetz. Determination of mass attenuation coefficient by numerical absorption calibration with Monte-Carlo simulations at $59.54 \mathrm{keV}$. Nuclear Instruments and Methods in Physics Research Section A: Accelerators, Spectrometers, Detectors and Associated Equipment, 2016, 816, pp.47-52. 10.1016/j.nima.2016.01.075 . hal-01315381

\author{
HAL Id: hal-01315381 \\ https://hal.science/hal-01315381
}

Submitted on 13 May 2016

HAL is a multi-disciplinary open access archive for the deposit and dissemination of scientific research documents, whether they are published or not. The documents may come from teaching and research institutions in France or abroad, or from public or private research centers.
L'archive ouverte pluridisciplinaire HAL, est destinée au dépôt et à la diffusion de documents scientifiques de niveau recherche, publiés ou non, émanant des établissements d'enseignement et de recherche français ou étrangers, des laboratoires publics ou privés. 


\title{
Determination of mass attenuation coefficient by numerical absorption calibration with Monte-Carlo simulations at 59.54 $\mathrm{keV}$
}

\author{
D. Degrelle ${ }^{\mathrm{a}}$, C. Mavon ${ }^{\mathrm{a}}$, J.-E. Groetz ${ }^{\mathrm{a}, *}$ \\ ${ }^{a}$ Laboratoire Chrono-Environnement, UMR CNRS 6249, Université de Bourgogne Franche-Comté, \\ F-25030 Besançon, France
}

\begin{abstract}
This study presents a numerical method in order to determine the mass attenuation coefficient of a sample with an unknown chemical composition at low energy. It is compared with two experimental methods : a graphic method and a transmission method. The method proposes to realise a numerical absorption calibration curve to process experimental results. Demineralised water with known mass attenuation coefficient $(0.2066$ $\mathrm{cm}^{2} \cdot \mathrm{g}^{-1}$ at $59.54 \mathrm{keV}$ ) is chosen to confirm the method. $0.1964 \pm 0.0350 \mathrm{~cm}^{2} \cdot \mathrm{g}^{-1}$ is the average value determined by the numerical method, that is to say less than $5 \%$ relative deviation compared to more than $47 \%$ for the experimental methods.
\end{abstract}

Keywords: Mass attenuation coefficient; Gamma spectrometry; Self-absorption; Monte-Carlo method; Transmission geometry

\section{Introduction}

Geochronologic methods with natural radioisotopes, such as ${ }^{210} \mathrm{~Pb},{ }^{7} \mathrm{Be}$ and anthropogenic ones $\left({ }^{137} \mathrm{Cs}\right)$, make the determination of geologic characteristics possible; sedimentation speed and rate, bioturbation and sediment's age [1]. In order to quantify the gamma photons emitted by these isotopes, the commonly used method is the gamma spectrometry. The quantification of ${ }^{210} \mathrm{~Pb}$ is often used for environmental sample dating $[2-4]$. This isotope originates through the decay of ${ }^{238} \mathrm{U}$ which is found in most soil. ${ }^{226} \mathrm{Ra}$ is a transitional daughter which produces gaseous ${ }^{222} \mathrm{Rn}$. A proportion of ${ }^{222} \mathrm{Rn}$ decays to ${ }^{210} \mathrm{~Pb}$ within the soil (called the supported ${ }^{210} \mathrm{~Pb},{ }^{210} \mathrm{~Pb}_{\text {supp }}$ ) which is in equilibrium with the parent ${ }^{226} \mathrm{Ra}$. Another proportion of gaseous ${ }^{222} \mathrm{Rn}$ decays into the atmosphere. The produced ${ }^{210} \mathrm{~Pb}$ (called the excess ${ }^{210} \mathrm{~Pb},{ }^{210} \mathrm{~Pb}_{\mathrm{ex}}$ ) is quickly deposited as fallout and is not in equilibrium with its parent. The quantification of ${ }^{210} \mathrm{~Pb}$ by gamma spectrometry is realised through its emitted gamma rays at low energy (46.5 $\mathrm{keV})$. The measure of this photoelectric peak gathers both parts of ${ }^{210} \mathrm{~Pb}$ together, but sample dating is carried out by quantification of excess ${ }^{210} \mathrm{~Pb}$. The amount of ${ }^{210} \mathrm{~Pb}_{\mathrm{ex}}$ is

*Corresponding author Tel. : + 33381666507 ; fax: + 33381666522

Email address: jegroetz@univ-fcomte.fr (J.-E. Groetz)

Preprint submitted to Nucl. Instrum. Meth. A

January 21, 2016 
determined by subtracting ${ }^{210} \mathrm{~Pb}_{\text {supp }}$, which is in equilibrium with ${ }^{226} \mathrm{Ra}$, from the ${ }^{210} \mathrm{~Pb}$ total activity. The counting at such a low energy as $46.5 \mathrm{keV}$ requires a broad energy or $\mathrm{N}$ type detector. However the photons are affected by self-absorption phenomena. These effects prevent some photons from reaching the detector and induce an underestimated quantification [5]. Studying sediment activities involves calibrating the detector to find the efficiency curve for the considered geometry. The standard sample needs to have the same geometry, density and chemical composition as the studied sample, in order to make sure that the degree of self-absorption is the same between both samples. The ChronoEnvironment Laboratory uses the IAEA-447 moss-soil certified reference material [6]. This standard can take the desired geometry, but the exact composition is unknown. Moreover, chemical composition and density are not similar, due to the large range of soil's composition and the difficulty to prepare a sample with the same settlement.

The methods to overcome the self-absorption difference are:

1. apply a self-absorption correction between standard and studied sample $[7,8]$

2. perform a calibration of the efficiency with numerical calculation.

In the second method, the knowledge of the chemical composition is essential. This work proposes the determination of the mass attenuation coefficient at low energy. This coefficient is linked to the chemical composition through the following equation 1 :

$$
\mu_{m}=\Sigma\left(\mu_{m i} \cdot \omega_{i}\right)
$$

where $\mu_{m i}$ is the mass attenuation coefficient of element $i$ and $\omega_{i}$ is the mass percentage of element $i . \mu_{m}$ represents the attenuation of the photon beam, at a given energy, in matter. The determination of this coefficient makes it possible to define a virtual chemical composition which has the same attenuation characteristics as the studied sample. In other words, the sample and the virtual sample have the same degree of self-absorption (for a given density). The simulation can be carried out with the new virtual composition for lower energy to realise the efficiency curve. This work determines the mass attenuation coefficient of demineralised water at $59.54 \mathrm{keV}$. The results are compared with the theoretical value.

\section{Materials, device and simulation}

\subsection{Materials}

The used detector in this study is a planar BEGe detector (Broad Energy Germanium, model BE3825). It was manufactured by Canberra in 2014. The nominal efficiency is higher than 28\%, and its resolution is $1.72 \mathrm{keV}$ at $1332 \mathrm{keV}$. All spectra are analysed using the Genie 2000 software (Canberra) [9]. The dimensions and materials of this detector provided by manufacturers are shown in Fig. 1. The germanium crystal is surrounded by a low-background copper holder kept into a low-background aluminium end-cap in vacuum. The entrance window is made up of carbon-epoxy material. The dead layers are not included in Fig. 1. The front and the lateral dead layer are given respectively as $0.4 \mu \mathrm{m}$ and $0.6 \mathrm{~mm}$.

For measurements, a radioactive point source of ${ }^{241} \mathrm{Am}$ was used. It is sealed into thin plastic sheets and the dimensions of the active zone are $0.11 \mathrm{~mm}$ thickness and 3 $\mathrm{mm}$ diameter. The activity was $38,750 \mathrm{~Bq}$ when the measurements were carried out. 


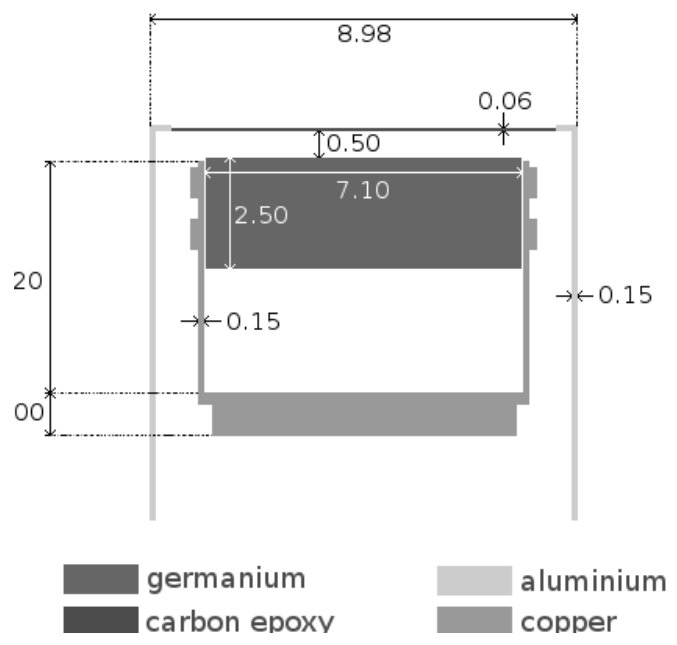

Figure 1: Geometry of the planar detector. All dimensions are given in centimetres.

${ }^{241} \mathrm{Am}$ emits gamma-ray at $59.54 \mathrm{keV}(35.9 \%)$ and enables to study the attenuation at low energy. The point source is collimated by a lead collimator in order to obtain a photon beam perpendicular to the detector window. The dimensions of the collimator are $5.05 \mathrm{~cm} \times 7.63 \mathrm{~cm}$, the hole's diameter is $0.19 \mathrm{~cm}$ and the height is $3.28 \mathrm{~cm}$.

The studied sample is water. The theoretical total mass attenuation coefficient of pure water $\left(\mathrm{H}_{2} \mathrm{O}\right)$ is $0.2066 \mathrm{~cm}^{2} \cdot \mathrm{g}^{-1}$ at $59.54 \mathrm{keV}$ [10]. Demineralised water was chosen in order to be closer to this attenuation coefficient, removing elements which could change this value. The density of the solution was determined by weighting the known water volume in a $25 \mathrm{~cm}^{3}$ volumetric flask. In the laboratory's temperature condition, the density of water is $0.9889 \pm 0.0079$ g. $\mathrm{cm}^{-3}$. The water solution was contained in a SG 50 standardised bottle.

\subsection{Experimental device}

The experimental device is shown in Fig. 2. In this configuration, all the photons which reach the germanium crystal have crossed the same thickness of the sample due to the position of the lead collimator. A plastic protection is inserted between the lead collimator and the carbon-epoxy window to protect the top of the detector from the collimator's mass. There is a hole (diameter $0.5 \mathrm{~cm}$ ) in its centre to avoid absorption in this material. This device was used for the three tested methods in this work.

\subsection{Monte-Carlo simulation}

The MCNP6 (Monte-Carlo N-Particle) code [12] was used for modelling the BEGe detector and the device of the study (section 2.2). The model was established based on the dimensions provided by the manufacturer (Fig. 1). The most suitable tally for modelling detector response is the F8 tally which provides the energy distribution of pulses created by gamma photons in the detector.

Each run used $10^{9}$ histories and the uncertainties on the number of counts are about $1.8 \%$ maximum for the photopeak including the region of interest at $59.54 \mathrm{keV}$. 


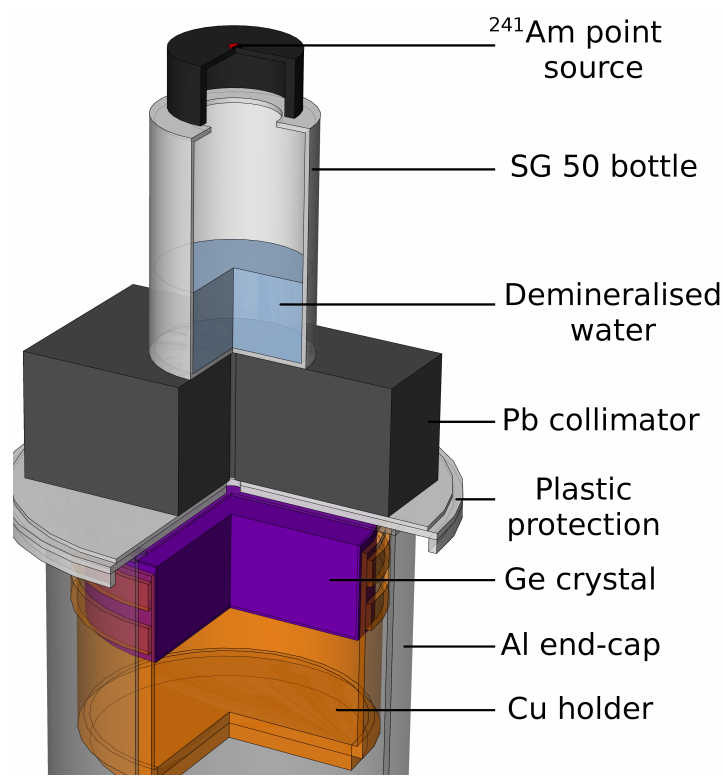

Figure 2: Sectional view of the experimental device as implemented in SimpleGeo 4.3 [11]

The compatibility between the simulated results and the experimental ones (for the same device and the same sample) is very important in order to validate the detector model, and it must be checked first. If these results are different, a correction factor must be found. The correction factor $f$ can be expressed as:

$$
f=\frac{N(\exp )}{N(\mathrm{MCNP} 6)}
$$

To define $f$, an experiment with the device (section 2.2) was carried out with an empty SG 50 bottle for an active time of $5 \mathrm{~h}$. The geometry of the device was implemented in MCNP6 and a simulation was done with $10^{9}$ histories. The results are $N(\exp )=$ 14203 net counts and $N(\mathrm{MCNP} 6)=18466$ net counts. The correction factor is $f=$ 0.77 for the photopeak at $59.54 \mathrm{keV}$. A difference like this one could be explain by the detector's characteristics given by the manufacturer. Some features can be incomplete or not accurate. For example, the existence of screws which hold the germanium crystal or the tilt of the crystal in the aluminium cap are never taken into account in the characteristics sheet [13]. The impact of the detector's geometry is important especially on gamma photons at low energy [14]. For upper energies, the correction factor is close to 1. This factor must be taken into account to realise the numerical absorption calibration at low energy.

\section{Methods and results}

The three following methods use the law of gamma photons attenuation through matter. The previous device explained in section 2.2 makes possible that the photon 
beam reaches the detector perpendicularly. In this configuration, all photons cross the same thickness of material and the attenuation of fluence (number of particles per unit of area) can be expressed as:

$$
\begin{gathered}
I=I_{0} \cdot \exp \left(-\mu_{T} \cdot h\right) \\
I=I_{0} \cdot \exp \left(-\mu_{m} . \rho . h\right)
\end{gathered}
$$

where $I_{0}$ and $I$ are the fluence before and after the attenuation respectively, $\mu_{T}$ is the total linear attenuation coefficient $\left(\mathrm{cm}^{-1}\right), \mu_{m}$ is the mass attenuation coefficient $\left(\mathrm{cm}^{2} \cdot \mathrm{g}^{-1}\right)$, $\rho$ is the density of the material (g.cm ${ }^{-3}$ ) and $h$ is the thickness of the crossed material $(\mathrm{cm})$.

To take into account the uncertainties, the repeatability of experiments was checked. Each measurement was realised 5 times with $5 \mathrm{~h}$ for the active time. This duration gave a good counting statistics and an average of number of net counts was carried out for the 5 measurements. The standard deviation of the experimental results is less than $2 \%$.

In order to know the uncertainties due to water thickness, the real crossed water thickness is defined with the known inserted water volume in the SG 50 bottle and the weighting of these volumes. The calculated thickness $h_{\text {calc }}$ can be expressed by Eq. 6:

$$
\begin{gathered}
V=\frac{m}{\rho}=\pi \cdot R^{2} \cdot h_{\text {calc }} \\
h_{\text {calc }}=\frac{m}{\pi \cdot R^{2} \cdot \rho}
\end{gathered}
$$

where $R=1.87 \mathrm{~cm}$ is the internal radius of the SG 50 bottle. The real crossed water thickness $h_{\text {calc }}$ is expressed in Table 1 .

An experiment is performed without the ${ }^{241} \mathrm{Am}$ point source according to the device in Fig. 2, in order to check if the demineralised water is free of ${ }^{241} \mathrm{Am}$ or other nuclides which emit gamma photons at energies close to $59.54 \mathrm{keV}$.

\begin{tabular}{lccccccccc}
\hline$h(\mathrm{~cm})$ & 0 & 0.5 & 1 & 1.5 & 2 & 2.5 & 3 & 3.5 & 4 \\
\hline$m(\mathrm{~g})$ & 0.00 & 5.32 & 11.52 & 16.76 & 22.01 & 26.51 & 32.22 & 37.05 & 43.11 \\
\hline$h_{\text {calc }}(\mathrm{cm})$ & 0.00 & 0.49 & 1.06 & 1.55 & 2.03 & 2.44 & 2.97 & 3.41 & 3.97 \\
\hline$\Delta h_{\text {calc }}$ & 0.00 & 0.00 & 0.01 & 0.01 & 0.02 & 0.02 & 0.03 & 0.03 & 0.03 \\
\hline
\end{tabular}

Table 1: Real crossed water thickness $h_{\text {calc }}$.

\subsection{Graphic method}

This method is an experimental one. It consists in measuring the counting area of the $59.54 \mathrm{keV}$ photoelectric peak in the configuration of the experimental device (section 2.2), varying the thickness of demineralised water [15] in the SG 50 bottle from $0 \mathrm{~cm}$ to $4 \mathrm{~cm}$ with a $0.5 \mathrm{~cm}$ increment. The net counts evolution as a function of water thickness can be expressed as a decreasing exponential curve, similar to the gamma photon attenuation law in matter. The results are expressed in Table 2 and the evolution of net counts as a function of water thickness is shown in Fig. 3.

We can notice that the fitting curve of experimental data is associated to the law of gamma photons attenuation (Eq. 3). From the equation of the fitting curve $\mu_{T}$ is equal to $0.1044 \pm 0.0022 \mathrm{~cm}^{-1}$. The density of demineralised water is $0.9889 \mathrm{~g} \mathrm{~cm}^{-3}$, 


\begin{tabular}{lccccccccc}
\hline Thickness $(\mathrm{cm})$ & 0 & 0.49 & 1.06 & 1.54 & 2.03 & 2.44 & 2.97 & 3.41 & 3.97 \\
\hline Average net counts & 14203 & 13054 & 12770 & 12017 & 11273 & 10442 & 10400 & 9760 & 9505 \\
\hline Standard deviation & 81 & 70 & 56 & 59 & 122 & 79 & 209 & 80 & 105 \\
\hline
\end{tabular}

Table 2: Number of net counts of the $59.54 \mathrm{keV}$ photopeak according to the crossed water thickness.

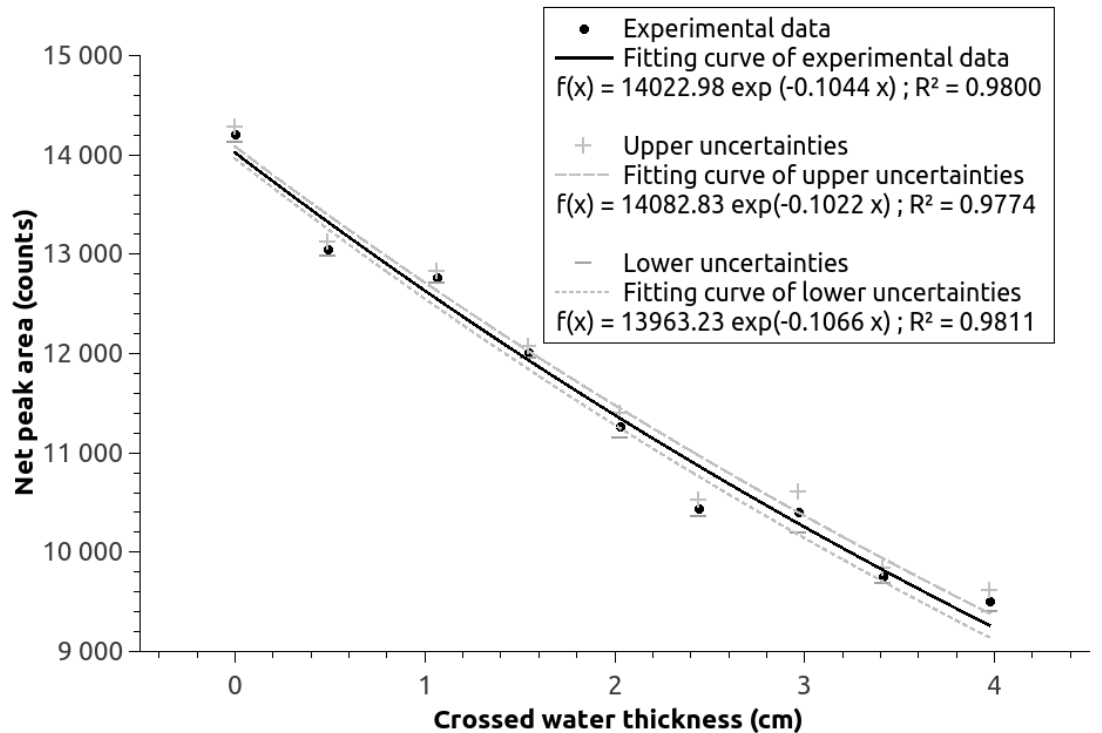

Figure 3: Attenuation of net counts in water for $59.54 \mathrm{keV}$ photopeak.

therefore, the mass attenuation coefficient is $0.1056 \pm 0.0023 \mathrm{~cm}^{2} \mathrm{~g}^{-1}$. The relative deviation associated to the theoretical value of the mass attenuation coefficient of water at $59.54 \mathrm{keV}$ is about $48.9 \%$ for this method.

\subsection{Transmission method}

This method is also an experimental one and refers to the work of Norman H. Cutshall et al. [16]. The principle of this method is to find the attenuation factor of a studied material, making a comparison between an attenuated beam by a given thickness of the studied material and a non-attenuated beam, without material, in the same configuration. In our case, the same method was used in order to determine the linear attenuation coefficient. Both configurations are shown in Fig. 4, where the beam is attenuated by demineralised water (a) and where the beam is not attenuated (b) (empty SG 50).

The situation (a) can be expressed as Eq. 7 and the situation (b) as Eq. 8:

$$
\begin{aligned}
N(\text { water }) & =N_{0} \cdot \exp \left[-\mu_{L} \text { (water) } . h\right] \\
N(\text { air }) & =N_{0} \cdot \exp \left[-\mu_{L} \text { (air). } h\right]
\end{aligned}
$$

where $\mu_{L}$ is the linear attenuation coefficient $\left(\mathrm{cm}^{-1}\right)$. Solving the previous equations for $N_{0}$, we get: 


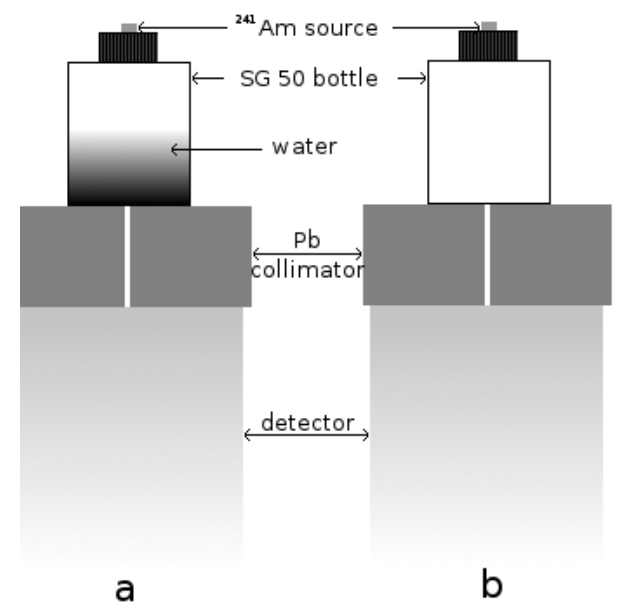

Figure 4: Both configurations for the transmission method.

$$
\begin{gathered}
N(\text { air }) \cdot \exp \left[\mu_{L}(\text { air }) \cdot h\right]=N(\text { water }) \cdot \exp \left[\mu_{L}(\text { water }) \cdot h\right] \\
\frac{N(\text { air })}{N(\text { water })}=\exp \left[h \cdot\left(\mu_{L}(\text { water })-\mu_{L}(\text { air })\right)\right] \\
\mu_{L}(\text { water })=\frac{1}{h} \cdot \ln \left[\frac{N(\text { air })}{N(\text { water })}\right]+\mu_{L}(\text { air })
\end{gathered}
$$

Eq. 11 makes it possible to calculate the mass attenuation coefficient $\left(\mu_{m}\right)$ with $\mu_{L}$ $=\mu_{m} . \rho$. The linear attenuation coefficient of air is taken as $0.0002 \mathrm{~cm}^{-1}$ (according to $\mu_{m}$ (air) $=0.1882 \mathrm{~cm}^{2} \cdot \mathrm{g}^{-1}$ at $59.54 \mathrm{keV} \mathrm{[10]} \mathrm{and} \rho$ (air) $=0.0012 \mathrm{~g} \mathrm{~cm}^{-3}$ ). The uncertainties associated to $\mu_{L}$ can be expressed as Eq. 12 [17], where uncertainties on $\mu_{L}($ air) are insignificant:

$$
\Delta^{2} \mu_{L}(\text { water })=\frac{1}{\mu^{2}} \cdot\left\{\frac{\Delta x^{2}}{x^{2}}+\ln \left(\frac{N(\text { air })}{N(\text { water })}\right)^{2} \cdot\left[\frac{\Delta N(\text { air })^{2}}{N(\text { air })^{2}}+\frac{\Delta N(\text { water })^{2}}{N(\text { water })^{2}}\right]\right\}
$$

The results are shown in Table 3 . The method shows similar results for a crossed water thickness greater than $1 \mathrm{~cm}$. An average is done on these values and the determined mass attenuation coefficient is $0.1095 \pm 0.0088 \mathrm{~cm}^{2} \mathrm{~g}^{-1}$. The relative deviation to the theoretical value of the mass attenuation coefficient of water at $59.54 \mathrm{keV}$ is about $47.0 \%$ for the transmission method.

\subsection{Method by numerical absorption calibration}

In view of the unacceptable relative deviation of both previous methods, a more accurate method must be found. To overcome this difference between the determined mass attenuation coefficient and the theoretical value, this work proposed a numerical method. It uses Monte-Carlo calculations in order to process the experimental results. 


\begin{tabular}{cccccccc}
\hline$h_{\text {calc }}(\mathrm{cm})$ & $\Delta h_{\text {calc }}$ & $N_{\text {net }}$ & $\Delta N_{\text {net }}$ & $\mu_{L}\left(\mathrm{~cm}^{-1}\right)$ & $\Delta \mu_{L}$ & $\mu_{m}$ & $\Delta \mu_{m}$ \\
\hline 0 & 0 & 14203 & 81 & - & - & - & - \\
0.49 & 0 & 13055 & 70 & 0.1722 & 0.0038 & 0.1741 & 0 \\
1.06 & 0.01 & 12770 & 56 & 0.1005 & 0.0942 & 0.1017 & 0.0008 \\
1.54 & 0.01 & 12017 & 59 & 0.1087 & 0.0608 & 0.1099 & 0.0005 \\
2.03 & 0.02 & 11273 & 122 & 0.1140 & 0.0899 & 0.1153 & 0.0007 \\
2.44 & 0.02 & 10442 & 79 & 0.1263 & 0.0689 & 0.1278 & 0.0006 \\
2.97 & 0.03 & 10400 & 209 & 0.1051 & 0.1143 & 0.1063 & 0.0009 \\
3.41 & 0.03 & 9760 & 80 & 0.1102 & 0.0867 & 0.1115 & 0.0007 \\
3.97 & 0.03 & 9505 & 105 & 0.1014 & 0.0899 & 0.1025 & 0.0007 \\
\hline
\end{tabular}

Table 3: Determination of $\mu_{m}$ (water) at $59.54 \mathrm{keV}$ for different crossed thicknesses with transmission method.

The aim of this method is to obtain a numerical absorption calibration curve of the area of the $59.54 \mathrm{keV}$ photo-peak as a function of the mass attenuation coefficient. This curve was realised by simulation with the MCNP6 code, with the same device (section 2.2). The water solution was replaced, in the material specification in the MCNP6 script, by several elements whose mass attenuation coefficients at $59.54 \mathrm{keV}$ are known. The elements are chosen in such a way that their mass attenuation coefficients encompass the searched mass attenuation coefficient (about $0.2066 \mathrm{~cm}^{2} \mathrm{~g}^{-1}$ at $59.54 \mathrm{keV}$ ). The chosen elements are shown in Table 4.

\begin{tabular}{lccccccc}
\hline Element & $\mathrm{Li}$ & $\mathrm{N}$ & $\mathrm{O}$ & $\mathrm{F}$ & $\mathrm{Ne}$ & $\mathrm{Na}$ & $\mathrm{Al}$ \\
\hline$\mu_{m}\left(\mathrm{~cm}^{2} \mathrm{~g}^{-1}\right)$ & 0.1440 & 0.1823 & 0.1915 & 0.1930 & 0.2175 & 0.2286 & 0.2808 \\
\hline
\end{tabular}

Table 4: Selected elements and their mass attenuation coefficients for numerical attenuation calibration at $59.54 \mathrm{keV}$, from the XCOM database [10]

Even if their mass attenuation coefficient are not close to $\mu_{m}$ (water), the elements lithium and aluminium are selected to take into account the prospective uncertainties. In order to avoid self-absorption due to density, the density of the element contained in the SG 50 bottle in the simulation must have the same density as water: $0.9889 \mathrm{~g} \mathrm{~cm}^{-3}$. In this case, the issues associated to the self-absorption phenomena are only based on the attenuation coefficient and not on the density.

Simulations were performed with $10^{9}$ histories and the results associated to the 59.54 $\mathrm{keV}$ net peak area must be corrected by the correction factor $f$ expressed in Eq. 2 . $N_{\text {corr }}$ is the net peak area after the correction. The simulated attenuation calibration was carried out for all the crossed water thicknesses. The results used to realise the attenuation calibration curves are shown in Table 5.

An example of these calibration curves is shown in Fig. 5. The crossed water thickness of this sample is $2.44 \mathrm{~cm}$. The error on the mass attenuation coefficient is taken into the parallelogram of uncertainties, drawn between simulated and experimental uncertainties.

The determined mass attenuation coefficients are expressed for each crossed water thicknesses in Table 6 . The average mass attenuation coefficient is $0.1964 \pm 0.0350 \mathrm{~cm}^{2}$ $\mathrm{g}^{-1}$. Its relative deviation to the theoretical value is about $4.9 \%$. 


\begin{tabular}{c|cc|cc|cc|cc}
\hline Water thickness & \multicolumn{2}{|c|}{$0.49 \mathrm{~cm}$} & \multicolumn{2}{|c|}{$1.06 \mathrm{~cm}$} & \multicolumn{2}{c|}{$1.54 \mathrm{~cm}$} & \multicolumn{2}{c}{$2.03 \mathrm{~cm}$} \\
\hline$\mu_{m}\left(\mathrm{~cm}^{2} \mathrm{~g}^{-1}\right)$ & $N_{\text {corr }}$ & $\Delta N_{\text {corr }}$ & $N_{\text {corr }}$ & $\Delta N_{\text {corr }}$ & $N_{\text {corr }}$ & $\Delta N_{\text {corr }}$ & $N_{\text {corr }}$ & $\Delta N_{\text {corr }}$ \\
\hline 0.1440 & 13570 & 179 & 12913 & 176 & 12397 & 173 & 11897 & 169 \\
0.1823 & 13411 & 179 & 12634 & 179 & 11974 & 171 & 11372 & 166 \\
0.1915 & 13375 & 179 & 12555 & 175 & 11870 & 171 & 11257 & 166 \\
0.1930 & 13373 & 179 & 12546 & 175 & 11856 & 171 & 11241 & 166 \\
0.2175 & 13274 & 178 & 12335 & 173 & 11605 & 169 & 10952 & 165 \\
0.2286 & 13234 & 177 & 12245 & 173 & 11481 & 167 & 10812 & 162 \\
0.2808 & 13026 & 176 & 11846 & 169 & 10984 & 164 & 10217 & 159 \\
\hline \hline Water thickness & \multicolumn{2}{|c|}{$2.44 \mathrm{~cm}$} & \multicolumn{2}{|c|}{$2.97 \mathrm{~cm}$} & \multicolumn{2}{c|}{$3.41 \mathrm{~cm}$} & $3.97 \mathrm{~cm}$ \\
\hline$\mu_{m}\left(\mathrm{~cm}^{2} \mathrm{~g}^{-1}\right)$ & $N_{\text {corr }}$ & $\Delta N_{\text {corr }}$ & $N_{\text {corr }}$ & $\Delta N_{\text {corr }}$ & $N_{\text {corr }}$ & $\Delta N_{\text {corr }}$ & $N_{\text {corr }}$ & $\Delta N_{\text {corr }}$ \\
\hline 0.1440 & 11488 & 168 & 11007 & 165 & 10620 & 161 & 10126 & 159 \\
0.1823 & 10923 & 164 & 10361 & 160 & 9893 & 157 & 9376 & 152 \\
0.1915 & 10789 & 162 & 10210 & 159 & 9726 & 155 & 9218 & 149 \\
0.1930 & 10775 & 163 & 10190 & 159 & 9708 & 154 & 9208 & 149 \\
0.2175 & 10445 & 160 & 9799 & 155 & 9334 & 152 & 8786 & 147 \\
0.2286 & 10284 & 159 & 9624 & 154 & 9150 & 151 & 8603 & 146 \\
0.2808 & 9617 & 154 & 8930 & 140 & 8435 & 146 & 7913 & 141 \\
\hline
\end{tabular}

Table 5: Corrected net peak area for $59.54 \mathrm{keV}$ photons beam, for each elements in SG 50 bottle and each crossed water thickness.

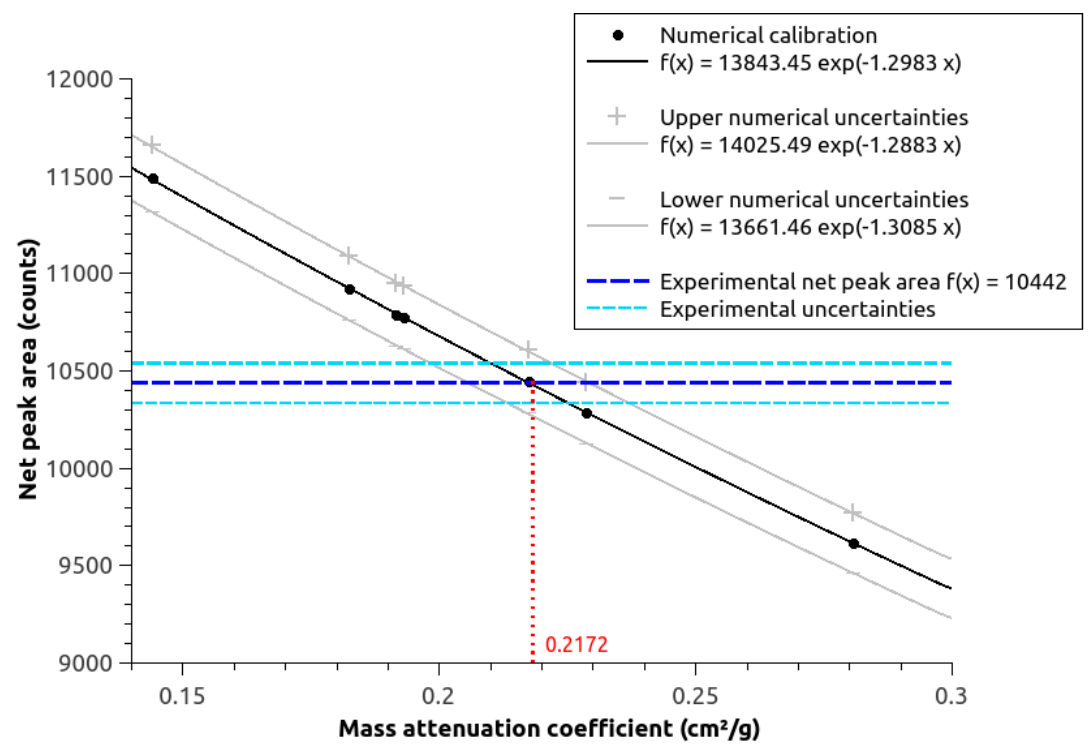

Figure 5: Attenuation calibration curve for $2.44 \mathrm{~cm}$ of crossed water thickness. The determined mass attenuation coefficient for this thickness is $0.2172 \mathrm{~cm}^{2} \mathrm{~g}^{-1}$.

\section{Discussion}

For every method, the relative deviation to the theoretical value was calculated. The average mass attenuation coefficient for the numerical method is closer to $\mu_{m}$ (water) 


\begin{tabular}{lcccccccc}
\hline Thickness $(\mathrm{cm})$ & 0.49 & 1.06 & 1.54 & 2.03 & 2.44 & 2.97 & 3.41 & 3.97 \\
\hline$\mu_{m}\left(\mathrm{~cm}^{2} \mathrm{~g}^{-1}\right)$ & 0.2737 & 0.1637 & 0.1782 & 0.1914 & 0.2172 & 0.1798 & 0.1913 & 0.1759 \\
\hline$\frac{\Delta \mu_{m}}{\mu_{m}}(\%)$ & 23.2 & 17.5 & 12.6 & 13.1 & 9.0 & 14.8 & 8.3 & 9.7 \\
\hline$\varepsilon(\%)$ & 32.5 & 20.8 & 13.7 & 7.4 & 5.1 & 13.0 & 7.4 & 14.9 \\
\hline
\end{tabular}

Table 6: Determined mass attenuation coefficient for each crossed water thickness with numerical attenuation calibration. $\varepsilon$ is the relative deviation to the theoretical value.

$\left(0.2066 \mathrm{~cm}^{2} \cdot \mathrm{g}^{-1}\right)$ with a $4.9 \%$ relative deviation, whereas for others methods the deviation is greater than $47 \%$.

In addition to the large deviations of results for the graphic method, this method is not suitable to find the attenuation coefficient for sediment or soil. Indeed, it requires to produce a sample with different heights but with the same density. Sediment and soil are reduced to a powder, and it is difficult to obtain the same settlement.

Concerning the transmission method, it only requires two experiments, with a filled SG 50 bottle and with an empty bottle. Only one sample has to be produced, independent of the density. The linear attenuation coefficient is inversely proportional to the crossed thickness (Eq. 11). The more the SG 50 bottle is filled, the more the attenuation coefficient is constant, as shown in Table 3. This means that the transmission method should not be used for small thicknesses, but beyond $1 \mathrm{~cm}$ [7].

Taking into account the large deviations, the graphic and the transmission methods are not selected in order to find the mass attenuation coefficient.

Concerning the method with the attenuation calibration, Table 6 and Fig. 6 show that all configurations are not suitable. According to these results, a water thickness of approximately $2.5 \mathrm{~cm}$ makes possible an accurate determination of the mass attenuation coefficient, compared to the theoretical value. On the contrary it can be noticed that the results for smaller water thickness give large deviations and uncertainties. This difference could be explained by the mean free path of $59.54 \mathrm{keV}$ photons crossing pure water. The average distance crossed in water by a $59.54 \mathrm{keV}$ photon, before an interaction takes place, is $4.9 \mathrm{~cm}\left(\lambda=\left[\mu_{m} . \rho\right]^{-1}\right)$. The self-absorption phenomenon is not strong enough for small water thicknesses $(0.5$ and $1 \mathrm{~cm})$ and may cause large deviations and uncertainties.

Contrary to the graphic method, the numerical method requires only one experiment. Therefore the method is suitable to find the mass attenuation coefficient for sediment, soil or others powders.

\section{Conclusion}

When the environmental sample dating is studied, one of the purposes is to perform efficiency calibration in order to make possible an accurate age estimation, especially if the ${ }^{210} \mathrm{~Pb}$ dating method is used. The experimental efficiency calibration is not suitable at low energy due to the self-absorption phenomenon between the studied sample and the standard one. Performing a simulated calibration of the efficiency could be a solution at low energy in order to free the efficiency curve from uncertainties owing to self-absorption. The chemical composition has to be implemented in the simulation. It is a characteristic which should be known. Our work makes it possible to determine the mass attenuation coefficient, which is linked to the chemical composition. A numerical method to calculate 


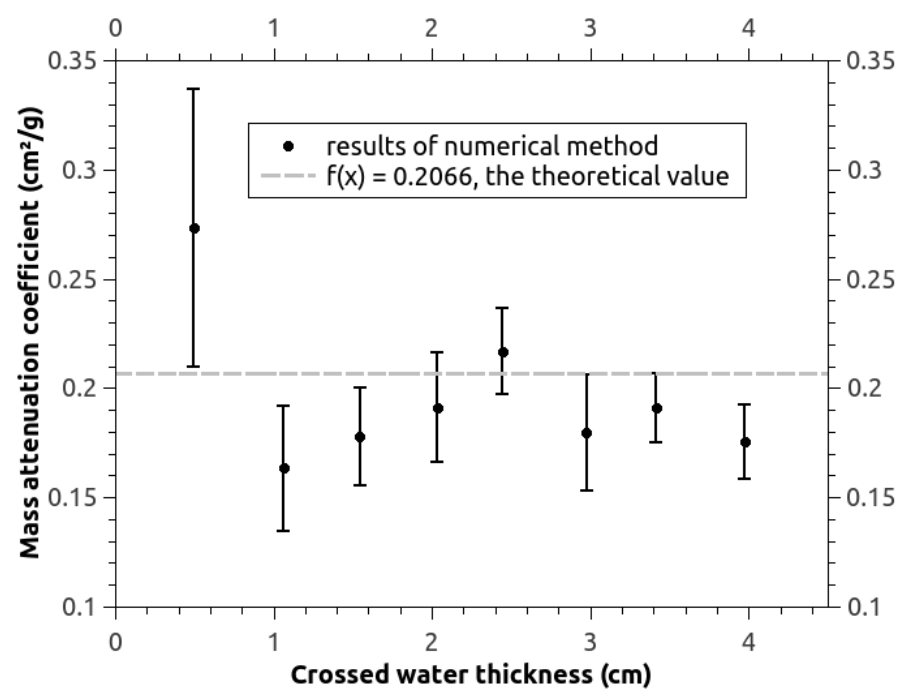

Figure 6: Determined mass attenuation coefficient and their uncertainties by numerical method, compared with theoretical value.

the mass attenuation coefficient of a well-known material such as demineralised water was proposed in this work and compared with two alternative methods: a graphic method and a transmission method. The choice of a water solution as sample allows us to approve the method by comparison with the theoretical value. In view of results, the study showed that numerical calculation is required in the attenuation coefficient determination. For the method by numerical absorption calibration, the relative deviation percentage is less than $5 \%$ unlike more than $47 \%$ for both other methods. It was also shown that the small thicknesses (up to $1 \mathrm{~cm}$ ) are not suitable and cause large deviations and uncertainties. The choice of only one configuration prevents from producing numerous samples with different thicknesses and with the same density if the study is carried out with sediment powder. As a reminder, the production of sample at the same density from a powder is difficult due to the settlement.

The determination of the attenuation coefficient makes it possible to find a virtual chemical composition with Eq. 1. This virtual composition has the same degree of self-absorption as the studied sample, at a given energy. It can be implemented in the simulation in order to obtain a simulated efficiency curve more accurate at low energy.

\section{References}

[1] L. Mabit, et al., Journal of Environmental Radioactivity 99 (2008) 1799.

[2] V. Putyrskaya, et al., Journal of Environmental Radioactivity 145 (2015) 78.

[3] J.A. Sanchez-Cabeza, A.C. Ruiz-Fernández, Geochimica et Cosmochimica Acta 82 (2012) 183.

[4] G. Kirchner, Journal of Environmental Radioactivity 102 (2011) 490.

[5] S. Kaminski, et al., Applied Radiation and Isotopes 94 (2014) 306.

[6] A. Shakhashiro, et al., Applied Radiation and Isotopes 70 (2012) 1632.

[7] P. Jodlowski, et al., Applied Radiation and Isotopes 87 (2014) 387.

[8] A.E.M. Khater, Y.Y. Ebaid, Applied Radiation and Isotopes 66 (2008) 407. 
[9] Genie 2000 3.3, Camberra Industries Inc., September 2013.

[10] M.J. Berger, et al., XCOM: Photon Cross Sections Database, NIST, Online at $<$ http://www.nist.gov/pml/data/xcom/index.cfm> (accessed on January 2016).

[11] C. Theis, et al., Nuclear Instruments and Methods in Physics Research A 562 (2006) 827.

[12] D.B. Pelowitz (Ed.), Los Alamos National Laboratory Report LA-CP-11-01708, Los Alamos, 2011.

[13] B. Blank, et al., Nuclear Instruments and Methods in Physics Research A 776 (2015) 34.

[14] R. Luís, et al., Nuclear Instruments and Methods in Physics Research A 623 (2010) 1014

[15] N.Q. Huy, et al., Applied Radiation and Isotopes 71 (2013) 11.

[16] N.H. Cutshall, et al., Nuclear Instruments and Methods 206 (1983) 309.

[17] M.-C. Lépy, et al., Applied Radiation and Isotopes 60 (2004) 159. 